Research

\title{
Elevated serum levels of soluble CDI54 in children with juvenile idiopathic arthritis
}

Sampath Prahalad*1, Thomas B Martins ${ }^{2}$, Anne E Tebo ${ }^{2,3}$, April Whiting1, Bronte Clifford ${ }^{1}$, Andrew S Zeft ${ }^{1}$, Bernadette McNally ${ }^{1}$, John F Bohnsack ${ }^{1}$ and Harry R Hill1,2,3,4

Address: ${ }^{1}$ Department of Pediatrics, University of Utah, Salt Lake City, UT, USA, ${ }^{2}$ The Associated Regional and University Pathologists Institute for Clinical and Experimental Pathology, Salt Lake City, UT, USA, ${ }^{3}$ Department of Pathology, University of Utah, Salt Lake City, UT, USA and ${ }^{4}$ Department of Medicine, University of Utah, Salt Lake City, UT, USA

Email: Sampath Prahalad* - prahal@genetics.utah.edu; Thomas B Martins - martintb@aruplab.com; Anne E Tebo - anne.tebo@aruplab.com; April Whiting - april.whiting@hsc.utah.edu; Bronte Clifford - bronte.clifford@hsc.utah.edu; Andrew S Zeft - andrew.zeft@hsc.utah.edu; Bernadette McNally - bernadette.mcnally@hsc.utah.edu; John F Bohnsack - john.bohnsack@hsc.utah.edu; Harry R Hill - harry.hill@path.utah.edu

* Corresponding author

Published: 28 May 2008

Pediatric Rheumatology 2008, 6:8 doi:10.1186/1546-0096-6-8
Received: 27 December 2007

Accepted: 28 May 2008

This article is available from: http://www.ped-rheum.com/content/6/1/8

(c) 2008 Prahalad et al; licensee BioMed Central Ltd.

This is an Open Access article distributed under the terms of the Creative Commons Attribution License (http://creativecommons.org/licenses/by/2.0), which permits unrestricted use, distribution, and reproduction in any medium, provided the original work is properly cited.

\begin{abstract}
Objective: Cytokines play important roles in mediating inflammation in autoimmunity. Several cytokines are elevated in serum and synovial fluid samples from children with Juvenile Idiopathic Arthritis (JIA). Soluble CDI54 (sCDI54) is elevated in other autoimmune disorders, but has not been characterized in JIA. Our objectives were to determine if SCDI54 is elevated in JIA, and to examine correlations between SCDI54 and other inflammatory cytokines.
\end{abstract}

Methods: Serum from 77 children with JIA and $8 I$ pediatric controls was analyzed for interleukin (IL) I $\beta$, IL2, IL4, IL5, IL6, IL8, ILI0, ILI2, ILI3, sCDI54, interferon- $\gamma$ (IFN $\gamma$ ), soluble IL2 receptor (sIL2R), and tumor necrosis factor- $\alpha$ (TNF $\alpha$ ), using the Luminex Multi-Analyte Profiling system. Differences in levels of cytokines between cases and controls were analyzed. Logistic regression was also performed.

Results: $\mathrm{sCD} 154$ was significantly elevated in cases compared to controls $(\mathrm{p}<0.000 \mathrm{I})$. ILI $\beta$, IL5, IL6, IL8, ILI 3, IFN $\gamma$, sIL2R, and TNF $\alpha$ were also significantly elevated in JIA. Levels of sCDI 54 were highly correlated with ILI $\beta$, IL6, IL8, and TNF $\alpha(p<0.000$ I). Logistic regression analysis suggested that IL6 (odds ratio (OR): I.4, $\mathrm{p}<0.000$ I), sCDI54 (OR: I.I, $\mathrm{p}<0.000$ I), and TNF $\alpha$ (OR: I.I, $\mathrm{p}$ $<0.005$ ) were positively associated with JIA, while ILIO (OR: $0.5, p<0.002$ ) was protective. $S C D I 54$ was elevated in all JIA subtypes, with highest levels among more severe subtypes. ILI $\beta$, IL6, IL8, sIL2R and TNF $\alpha$ were also elevated in several JIA subtypes.

Conclusion: Serum levels of sCDI54, ILI $\beta$, IL6, IL8, sIL2R and TNF $\alpha$ are elevated in most JIA subtypes, suggesting a major role for $\mathrm{SCDI} 54$, and these cytokines and cytokine receptors in the pathogenesis of JIA. 


\section{Background}

Juvenile idiopathic arthritis (JIA) is a heterogeneous group of arthropathies of unknown etiology. Both genetic and environmental factors are believed to play a role in susceptibility to JIA. One way to improve the understanding of the etiopathogenesis of JIA is to define better biological phenotypes of JIA. A common feature of the different subtypes of JIA is a tumor-like expansion of the inflamed synovial tissue, which is infiltrated by inflammatory cells including macrophages, plasma cells and lymphocytes. The production of inflammatory cytokines by these cells is thought to be instrumental in the development and perpetuation of the inflammatory arthritis. Several cytokines secreted by activated macrophages and lymphocytes such as interleukin (IL)1, IL6, and tumor necrosis factor- $\alpha$ (TNF $\alpha$ ) have been implicated in the perpetuation of inflammatory response in JIA [1]. Other studies have implicated IL1 $\beta$, IL6, IL8, soluble IL2-receptor (sIL2R), and TNF $\alpha$ in JIA [2-9].

CD40 is a member of the TNF-receptor family which is expressed on the surface of antigen presenting cells including B-cells, activated macrophages, dendritic cells and monocytes [10]. Signaling through CD40 induces antigen presenting cells to express different immune accessory molecules important in cell-cell interactions [11]. CD40 interacts with CD40 ligand (CD40L or CD154) which is predominantly expressed on activated CD4+ T-cells [12]. CD154 is transiently expressed on activated T-cells and plays a crucial role in B-cell function [13]. Activated T-cells expressing CD154 can also interact with CD40 on endothelial cells to induce production of inflammatory cytokines [14]. The transient expression of CD154 allows T-cells to stimulate selected CD40-bearing cells to participate in the immune response. Abnormal expression of CD154 has been reported in patients with systemic lupus erythematosus (SLE) and rheumatoid arthritis (RA) $[15,16]$.
In addition to existing in a membrane bound form, CD154 can also be released as a soluble molecule (sCD154), which has been shown to have biological functions [17]. Increased levels of sCD154 have been demonstrated in patients with SLE, [18], RA, [19], inflammatory bowel diseases (IBD) [20], systemic sclerosis [21,22] and Sjogren's syndrome [23]. To our knowledge the concentrations and possible role of sCD154 has not been investigated in JIA. Our objectives were to examine the levels of multiple cytokines including sCD154 in children with JIA and healthy controls, and to determine the association of sCD154 with other inflammatory cytokines reported to be elevated in JIA. We also sought to determine if sCD154 levels differed between the different subtypes of JIA.

\section{Methods}

Serum samples were obtained from 77 children (63\% female) who fulfilled the International League of Associations for Rheumatology (ILAR) criteria for the diagnosis of JIA [24]. There were 10 patients each with systemic JIA and rheumatoid factor (RF)-positive polyarticular JIA, 14 with RF-negative polyarticular JIA, 20 with persistent oligoarticular JIA, 11 with extended oligoarticular JIA and with enthesitis related arthritis (ERA), and 1 with undifferentiated arthritis. The mean age of onset of JIA in the patients was 7.5 years. A total of 81 pediatric controls (52\% female) were also studied with a mean age of 12 years (range $7-16$ years). Controls were children obtained from an Associated Regional and University Pathologists (ARUP) institute of clinical and experimental pathology children's normal values study. The majority of the cases and controls were of Northern European ancestry. Serum was separated from peripheral blood soon after being drawn from subjects and aliquots were stored at $-80^{\circ} \mathrm{C}$ until the time of cytokine determination. Subjects were enrolled after providing informed consent, under protocols approved by the Institutional Review Board of the University of Utah.

Table I: Disease activity and medication information of children with JIA

\begin{tabular}{|c|c|c|c|c|c|c|c|}
\hline Variable & All JIA & Systemic & $\mathrm{RF}$ & poly & Oligo & Ext & ERA \\
\hline Number & 77 & 10 & 10 & 14 & 20 & 11 & 11 \\
\hline Onset age (years) & 7.5 & 5.4 & 10 & 8.0 & 7.3 & 4.4 & 10.6 \\
\hline Median joints (n) & 2.5 & 5 & 8 & 7 & 2 & 2.5 & 3.5 \\
\hline ESR $(\mathrm{mm} \mathrm{Hg})$ & 23 & 49 & 26 & 17 & 18 & 28 & 11 \\
\hline Median number of medications & 1 & 2 & 1.5 & I & I & 1 & 1 \\
\hline Proportion on NSAIDS \% & 71 & 50 & 80 & 61.5 & 89 & 44 & 90 \\
\hline Proportion on DMARDS \% & 46 & 60 & 70 & 61.5 & 16 & 22 & 50 \\
\hline Proportion on methotrexate \% & 25 & 30 & 60 & 46.2 & 0 & 0 & 30 \\
\hline Proportion on an anti-TNF agent\% & 19 & 40 & 10 & 30 & 5 & 22 & 20 \\
\hline Proportion on Corticosteroids \% & 12.5 & 50 & 10 & 23 & 0 & 0 & 0 \\
\hline
\end{tabular}

NSAID: non steroidal anti-inflammatory drug, DMARD: disease modifying anti-rheumatic drug 
Information about disease variables at the time of enrollment was available on 72 children with JIA. Active disease was defined as having arthritis in at least 1 joint. Seven children did not have active disease. Variables collected included number of affected joints, ESR, and medications used to treat JIA at the time of enrollment (table 1). At the time of collection, $71 \%$ were on a non-steroidal anti inflammatory agent, $46 \%$ were on a disease modifying anti-rheumatic drug, 25\% were on methotrexate, $19 \%$ were on an anti-TNF agent, and $12 \%$ were on corticosteroids.

\section{Multiplexed Cytokine Assay}

The Luminex Multi-Analyte Profiling system (Luminex Corp, TX), is a flow cytometry based instrument that allows multiple analytes to be assayed simultaneously in a single sample [25]. The technology is based on the process of internally labeling $5.6 \mu \mathrm{m}$ polystyrene microspheres with two fluorescent fluorophores. As the microsphere passes through the flow cell, it is interrogated by two lasers. One laser identifies the microsphere based on the ratio of the two fluorophores contained within the microsphere, while the other laser quantitates the amount of analyte bound to the microsphere by the intensity of reporter fluorescence. The surface of each microsphere contains multiple carboxyl groups that function as sites for covalent ligand attachment. The amount of analyte bound to the microspheres is determined by the median fluorescence intensity (MFI) of the reporter molecule, phycoerythrin, which is conjugated to a secondary or "detection" antibody.

The multiplexed cytokine assay we used was developed in the ARUP Institute for Clinical and Experimental Pathol- ogy, University of Utah using a standard sandwich capture format and has been described previously [26,27]. Briefly, monoclonal antibodies to human IL1 $\beta$, IL2, IL4, IL5, IL6, IL8, IL10, IL12 p70, IL13, sCD154, IFN $\gamma, \operatorname{sIL2R} \alpha$, and TNF $\alpha$ were used as capture antibodies and coupled to carboxylated Luminex microspheres using a two-step carbodiimide reaction [28]. A standard curve for each cytokine was made using known concentrations of recombinant human cytokine. The subject's sample $(75 \mu \mathrm{l})$ was diluted 1:2 using a sample diluent and incubated for 10 minutes on an orbital plate shaker before the addition of the capture antibody coupled microspheres to allow for absorption of heterophile antibodies [27]. The cytokine standards, control samples, patient samples and microspheres were incubated for 1 hour at room temperature on an orbital plate shaker using 96-well filter bottom microtiter plate (Millipore Corporation, MA) to allow for subsequent washing by vacuum filtration. This was followed by the addition of $100 \mu$ l of a mixture of 13 different biotinylated secondary monoclonal antibodies to complete the sandwich capture assay. Following a second 30 minute incubation on the orbital plate shaker and washing, $100 \mu \mathrm{l}$ of $5 \mu \mathrm{g} / \mathrm{mL}$ of streptavidin conjugated Rphycoerythrin (Moss Substrates, MD) was added to each well. After a 15-minute incubation and final wash, the microspheres were resuspended in $100 \mu \mathrm{l}$ of PBST (10 $\mathrm{mM}$ phosphate buffered saline with $0.02 \%$ Tween 20), and the 96-well microplate was placed in a Luminex 100 instrument with an automated microtiter plate handler. The MFI of the unknown subject's sample was then converted into a $\mathrm{pg} / \mathrm{mL}$ value based on the known cytokine concentrations of the standard curve using a 5-parameter regression formula.

Table 2: Serum cytokine levels in healthy pediatric controls and in patients with JIA.

\begin{tabular}{|c|c|c|c|c|c|c|c|}
\hline \multirow[b]{2}{*}{ Cytokine } & \multicolumn{3}{|c|}{$\begin{array}{c}\text { Controls } \\
N=8 I\end{array}$} & \multicolumn{3}{|c|}{$\begin{array}{c}\text { Cases } \\
N=77\end{array}$} & \multirow[t]{2}{*}{$P$ value } \\
\hline & Mean & Median & IQR & Mean & Median & IQR & \\
\hline ILI $\beta$ & 6.8 & 0.6 & $0-3.5$ & 120.9 & 11 & $3.4-73$ & $<0.0001$ \\
\hline IL2 & 1.3 & 0 & $0-0$ & 12.9 & 0 & $0-0$ & 0.31 \\
\hline IL4 & 0.6 & 0 & $0-0.2$ & 5 & 0 & $0-0.9$ & 0.07 \\
\hline IL5 & 0.2 & 0 & $0-0$ & 7.7 & 0.4 & $0-1.6$ & $<0.0001$ \\
\hline IL6 & 1.7 & 0.6 & $0-1.8$ & 196.7 & 14.2 & $4.8-114$ & $<0.0001$ \\
\hline IL8 & 2.3 & 2 & $0-4.2$ & 149.5 & 19.3 & $0.6-91.3$ & $<0.0001$ \\
\hline ILIO & 3.3 & 2.0 & $1.6-3.2$ & 8.2 & 2.9 & I.3-8.4 & 0.07 \\
\hline ILI 2 & 5.4 & 0 & $0-3.2$ & 3.9 & 0 & $0-1.4$ & 0.44 \\
\hline ILI3 & 0.8 & 0 & $0-0.4$ & 178.7 & 19 & $0-181.1$ & $<0.0001$ \\
\hline sCDI54 & 58.2 & 19 & $4.2-73.2$ & 336.1 & 211.4 & |48.7-363.9 & $<0.0001$ \\
\hline IFN $\gamma$ & 0.3 & 0 & $0-0$ & 4 & 0 & $0-0$ & 0.001 \\
\hline SIL2R & 796.8 & 785.1 & $611.8-962.9$ & 1125 & 967.3 & $553.7-1436.9$ & 0.026 \\
\hline TNF $\alpha$ & 2.9 & 0 & $0-0$ & 88.5 & 15 & $0-70.7$ & $<0.0001$ \\
\hline
\end{tabular}

IQR, Interquartile range; IL, Interleukin; sCDI54, soluble CDI54; IFN $\gamma$, interferon- $\gamma$; sIL2R, soluble IL2 receptor; TNF $\alpha$, tumor necrosis factor- $\alpha$; All values median (range) are expressed in $\mathrm{pg} / \mathrm{ml}$. 


\section{Statistical Analysis}

Results are expressed as means, median and inter-quartile ranges. As most of the cytokine levels were not distributed normally, Wilcoxon two-sample tests were used to compare levels of cytokines between cases and controls. Correlations were determined using the Spearman's rank order correlation test. We also performed a stepwise logistic regression analysis to evaluate the effect of different cytokines on disease status. To make the ranges comparable, levels of sCD154 and sIL2R were divided by a factor of 10 for the regression analysis. Odds ratios (OR) and 95\% confidence intervals were calculated. The Hosmer and Lemeshow statistic was calculated to assess the goodness-of-fit of the regression model. Goodness-of-fit statistics examine the difference between the observed frequency and expected frequency for groups of patients. A p value $<0.05$ would suggest that the model is not well calibrated. Secondary analyses included comparison of cytokine levels between different JIA subtypes versus controls. We also compared the disease activity and treatment characteristics of children in the top tertile for sCD154 with those in the lower tertile. All comparisons were performed using SAS 9.1.

\section{Results}

The serum levels of IL1 $\beta$, IL5, IL6, IL8, IL13, sCD154, IFN $\gamma$, sIL2R, and TNF $\alpha$ were highly significantly elevated in cases compared to the controls (Table 2). Levels of IL2, IL4, IL10 and IL12 were not significantly different between cases and controls. The levels of IL2, IL4, IL5, and IFN $\gamma$ were lower than $5 \mathrm{pg} / \mathrm{ml}$ in over $90 \%$ of subjects, while the levels of IL12 were lower than $5 \mathrm{pg} / \mathrm{ml}$ in $85 \%$ of subjects. The median levels of IL2, IL4, IL5, IL12, and IFN $\gamma$, were $\sim 0 \mathrm{pg} / \mathrm{ml}$ among both cases and controls (Table 2). For this reason, these five cytokines were not included in subsequent analyses.

\section{Correlation and regression analyses}

When we performed correlation analyses, we found that sCD154 was highly positively correlated with the proinflammatory cytokines IL1 $\beta$, IL6, IL8 and TNF $\alpha$ (p < $0.0001)$, and is also positively correlated with sIL2R and IL13 ( $\mathrm{p}<0.01$ ) (Table 3). We also tested whether sCD154 levels had a relationship to age to determine if there were age related changes in our cohorts. There were no correlations between age at the time of collection, and levels of sCD154 or any of the other cytokines. When we examined correlations between disease activity variables and cytokine levels in cases, we found that ESR positively correlated with IL6 ( $\mathrm{p}<0.02)$, and number of joints $(\mathrm{p}<$ $0.02)$. The levels of TNF $\alpha$ correlated positively with the number of joints $(\mathrm{p}<0.05)$ and number of medications $(\mathrm{p}<0.003)$. There were no correlations between sCD154 levels and disease activity variables.

Since these cytokines were correlated with each other, we performed regression analyses. The Hosmer and Lemeshow goodness of-fit statistic was not-significant ( $\mathrm{p}>$ 0.11) suggesting the model is well calibrated and fits agreeably with the data. The logistic regression procedure identified four cytokines with statistical significance: IL6 with an OR of $1.4(1.19-1.67, \mathrm{p}<0.0001)$, IL10 with OR of $0.46(0.30-0.69, \mathrm{p}<0.001)$, TNF $\alpha$ with an OR of 1.08 $(1.02-1.13, \mathrm{p}<0.005)$ and sCD40 with OR of 1.14 (1.07 to $1.21 . \mathrm{p}<0.0001)$.

\section{Comparisons of cytokine levels among JIA subtypes and controls}

We also compared the cytokine levels between patients with different JIA subtypes and healthy controls (Table 4). sCD154, IL1 $\beta$, IL6 and TNF $\alpha$ levels were remarkably elevated in all subtypes compared to controls albeit at different levels of significance (Table 4 and figure 1). Of note,

Table 3: Spearman Correlation Coefficients of the cytokines.

\begin{tabular}{|c|c|c|c|c|c|c|c|c|}
\hline & ILI $\beta$ & IL6 & IL8 & ILIO & ILI3 & sCDI54 & sIL2R & TNF $\alpha$ \\
\hline \multirow[t]{2}{*}{ ILI $\beta$} & 1.00 & 0.65 & 0.54 & 0.46 & 0.37 & 0.55 & 0.28 & 0.63 \\
\hline & & $<.0001$ & $<.0001$ & $<.0001$ & $<.0001$ & $<.0001$ & 0.0003 & $<.0001$ \\
\hline \multirow[t]{2}{*}{ IL6 } & & 1.00 & 0.59 & 0.46 & 0.30 & 0.47 & 0.31 & 0.63 \\
\hline & & & $<.0001$ & $<.0001$ & 0.0001 & $<.0001$ & $<.0001$ & $<.0001$ \\
\hline \multirow[t]{2}{*}{ IL8 } & & & 1.00 & 0.29 & 0.18 & 0.38 & 0.17 & 0.44 \\
\hline & & & & 0.0002 & 0.03 & $<.0001$ & 0.0327 & $<.0001$ \\
\hline \multirow[t]{2}{*}{ ILIO } & & & & 1.00 & 0.27 & 0.20 & 0.46 & 0.35 \\
\hline & & & & & 0.0006 & 0.0107 & $<.0001$ & $<.0001$ \\
\hline \multirow[t]{2}{*}{ ILI3 } & & & & & 1.00 & 0.22 & 0.19 & 0.32 \\
\hline & & & & & & 0.0057 & 0.017 & $<.0001$ \\
\hline \multirow[t]{2}{*}{ sCDI54 } & & & & & & 1.00 & 0.23 & 0.45 \\
\hline & & & & & & & 0.0038 & $<.0001$ \\
\hline \multirow[t]{2}{*}{ sIL2R } & & & & & & & 1.00 & 0.29 \\
\hline & & & & & & & & 0.0002 \\
\hline TNF $\alpha$ & & & & & & & & 1.00 \\
\hline
\end{tabular}

IL, Interleukin; sCDI54, soluble CD I54; IFN $\gamma$, interferon- $\gamma$; sIL2R, soluble IL2 receptor; TNF $\alpha$, tumor necrosis factor- $\alpha$; Spearmann correlation coefficients between various pairs of cytokines and $\mathrm{p}$ values are shown. 
Table 4: Cytokine levels in sera of healthy controls and in patients with different JIA subtypes.

\begin{tabular}{|c|c|c|c|c|c|c|c|}
\hline Cytokine & $\begin{array}{l}\text { Controls } \\
N=130\end{array}$ & $\begin{array}{c}\text { Systemic } \\
N=10\end{array}$ & $\begin{array}{c}\text { Poly RF+ } \\
\mathbf{N}=10\end{array}$ & $\begin{array}{c}\text { Poly RF- } \\
N=14\end{array}$ & $\begin{array}{c}\text { Persistent } \\
\text { oligo } \\
\mathbf{N}=\mathbf{2 0}\end{array}$ & $\begin{array}{c}\text { Extended } \\
\text { Oligo } \\
\mathrm{N}=\mathrm{I} \text { I }\end{array}$ & $\begin{array}{c}\text { ERA } \\
\mathbf{N}=\text { II }\end{array}$ \\
\hline ILI $\beta$ & $0.6(0-143)$ & $6.8(3-407)^{\S}$ & $100.4(0-1000)^{\S}$ & $13.4(0-1000)^{\S}$ & $5.6(0-289)^{\dagger}$ & $29.7(0-1000)^{\ddagger}$ & $6.3(1-656)^{\dagger}$ \\
\hline IL6 & $0.6(0-19)$ & $34.2(3-980)^{\S}$ & $36(1-1000)^{\prime}$ & $17(0.9-1000) \S$ & $7.6(1-1000)^{\S}$ & $5.6(1-1000)^{\S}$ & $14.2(2-99)^{\S}$ \\
\hline IL8 & $2(0-9)$ & $14.2(0-103)^{\ddagger}$ & $62.6(0-1000)^{\S}$ & $63.3(0-1000)^{\dagger}$ & $12.4(0-380)^{\S}$ & $20.3(0-1000)$ & $0(0-8 I)$ \\
\hline ILIO & $2.0(0-32)$ & $6.7(I-46)^{*}$ & $7.1(1-40)^{*}$ & $3.9(1-14)^{*}$ & $1.8(0-42)$ & $1.8(0-10)$ & $2.7(1-76)$ \\
\hline ILI 3 & $0.8(0-15)$ & $0(0-427)$ & $83.3(0-1152)^{\ddagger}$ & $48.4(0-980)^{\dagger}$ & $0(0-1300)^{*}$ & $19(0-396)^{*}$ & $19.4(0-1367)^{*}$ \\
\hline sCDI54 & $19(0-599)$ & $327(89-609)^{\S}$ & $408(35-2382)^{\S}$ & $203(40-596)^{\S}$ & $180(0-390) *$ & $180(60-360)^{\S}$ & $379(57-2996)^{\S}$ \\
\hline SIL2R & $785(180-1505)$ & $\begin{array}{c}1184(703- \\
3000)^{\ddagger}\end{array}$ & $\begin{array}{c}1057(174- \\
2662)^{*}\end{array}$ & $\begin{array}{c}1355(176- \\
3000)^{*}\end{array}$ & $501(100-1762)$ & $895(273-2173)$ & $822(36 I-3000)$ \\
\hline TNF $\alpha$ & $0(0-233)$ & $22.8(0-335)^{\S}$ & $47.6(0-564)^{\S}$ & $24.3(0-498)^{\S}$ & $0(0-191)^{*}$ & $66.8(0-435)^{\S}$ & $15(0-1000)^{\S}$ \\
\hline
\end{tabular}

Poly RF+, rheumatoid factor positive polyarticular JIA; Poly RF-, rheumatoid factor negative polyarticular JIA; oligo, oligoarticular JIA; ERA, enthesitis related arthritis; IL, Interleukin; sCD I54, soluble CDI54; sIL2R, soluble IL2 receptor; TNF $\alpha$, tumor necrosis factor- $\alpha$; All values median (range) are expressed in $\mathrm{pg} / \mathrm{ml}$. Values of sIL2R and sCD40L levels, as well as ranges of all cytokines have been rounded to the nearest number.

* Significant difference between controls and patients; $p<0.05$.

$¥$ Significant difference between controls and patients; $p<0.01$

† Significant difference between controls and patients; $p<0.001$;

$\S$ Significant difference between controls and patients; $p<0.0001$.

sCD154 levels were most increased in children with RF+ polyarticular and systemic JIA as well as ERA than in the other types of disease. The highest levels of IL1 $\beta$ was seen in patients with RF+ polyarticular JIA while IL6 was most elevated in patients with systemic and polyarticular JIA. IL8, IL10 and IL13 were significantly elevated in specific JIA subtypes compared to controls (Table 4). The highest levels of IL8 and IL13 were observed in children with polyarticular JIA. IL10 was significantly elevated in polyarticular as well as systemic JIA. Lastly, sIL2R was most associated with the more severe forms of JIA namely; systemic, RF+ and RF- polyarticular JIA.

\section{Comparison of $s C D I 54$ levels with disease activity}

When we compared children in the top tertile for sCD154 with those in the lower tertile, those in the upper tertile had a greater ESR (28 vs. 14) and greater median number of joints (4.5 vs. 2$)$, but these differences were only marginally significant $(\mathrm{p}<0.09)$. There were no statistically significant differences in the proportion of those on NSAIDs, disease modifying anti-rheumatic agents, methotrexate or anti-TNF agents between children in the top tertile for sCD154 and those in the lower tertile.

\section{Discussion}

Utilizing a multiplex assay for cytokines and inflammatory markers, we characterized the profile of these biomarkers in a well defined cohort of JIA patients and controls. We observed striking elevations of a number of cytokines. Of special interest to us were the increased serum levels of sCD154 in children with different JIA subtypes. This elevation was most pronounced in children with systemic, RF-positive polyarticular and ERA subtypes, and modest among children with the oligoarticular subtypes. To our knowledge, ours is the first study to investigate sCD154 levels in JIA. Elevated levels of sCD154 have been found in other autoimmune disorders including SLE, RA, IBD, systemic sclerosis and Sjogren's syndrome [18-23]. Expression of CD40 on synovial monocytes, fibroblasts and dendritic cells in RA has been reported $[29,30]$. After stimulation in vitro, peripheral blood T-cells from patients with RA had increased and longer expression of CD154 compared to T-cells from controls [16]. Blocking CD40 on synovial fibroblasts from RA patients with soluble anti-CD40 antibodies prior to co-culture with synovial mononuclear cells resulted in decreased TNF $\alpha$ levels [16]. Moreover, blockade of CD154 with an antibody ameliorates collagen induced arthritis in a murine model of RA [31]. These observations suggest a major role for CD154 in the perpetuation of inflammation in RA.

The inflammation in synovial tissue of children with JIA is characterized by the presence of antigen presenting cells and activated T-cells, and is indistinguishable from the pathology observed in patients with RA [32]. Our results suggest that sCD154 might also play a role in the pathogenesis of most of the JIA subtypes. It is conceivable that the activated CD4 T-cells in JIA synovium may be the source of sCD154, although it is possible that other cells, such as activated platelets release sCD154. Cell-bound as well as sCD154 have been shown to activate endothelial cells in vitro, and increase production of leukemia inhibitory factor, IL6 and granulocyte-macrophage colony stimulating factors [14]. We speculate that sCD154 could possibly interact with cells bearing CD40, possibly enhancing antigen presentation, and production of other inflammatory mediators in JIA. 


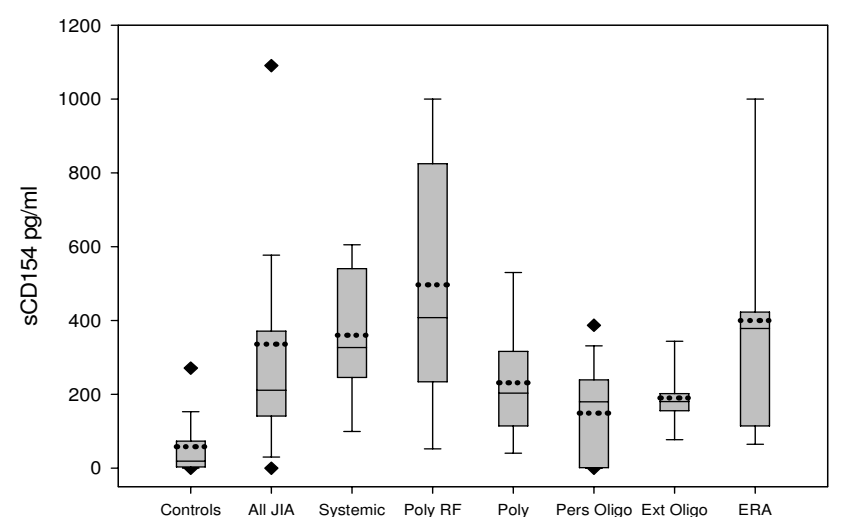

Figure I

sCDI54 Levels among controls and children with different JIA subtypes. Levels of sCDI 54 in different JIA subtypes. The boundaries of the boxes correspond to the $25^{\text {th }}$ and $75^{\text {th }}$ percentile. The solid horizontal line within the box denotes the median value and the dashed lines represent the mean values. The Whiskers above and below the boxes show the $90^{\text {th }}$ and $10^{\text {th }}$ percentiles respectively. Four subjects had levels greater than $1000 \mathrm{pg} / \mathrm{ml}$.

Our correlation analyses showed significant association between SCD154 and the pro-inflammatory markers IL6, IL1 $\beta$, IL8 and TNF $\alpha$. It has been shown that SCD154 has the potential to activate endothelial cells in vitro, and increase production of IL6 [14]. Elevated levels of IL6 in JIA have been reported by several authors [2-7,33,34]. Indeed, levels of IL6 were strikingly higher among all JIA subtypes compared to controls in our study. IL6 was also significant in the logistic regression analysis suggesting that it likely plays a major role in concert with other cytokines in the pathogenesis of JIA. The increased levels of the pro-inflammatory cytokines IL1 $\beta$ and IL8 observed in our cohort have also been reported in different forms of JIA as well as RA $[3-5,8,35]$. In agreement with earlier findings, we observed that levels of TNFa were elevated in all subtypes except those with persistent oligoarticular JIA, in which fewer joint involvement and less systemic inflammation is observed $[6,8]$. Together these observations support a primary or secondary role for the inflammatory cytokines IL6, IL1 $\beta$, IL8 and TNF $\alpha$ in different JIA subtypes.

The elevated levels of sIL2R and IL10 in the different subtypes of JIA are in agreement with previous studies $[2,6,9]$ although with some subtle differences which may be attributable to the differences in the size of the cohorts. For example, although we observed increased levels of sIL2R in a JIA subtype equivalent to ERA in a study by Mangge et al [8], these concentrations were not signifi- cantly different from controls. Nevertheless, sIL2R levels tend to be highest in systemic or polyarticular JIA suggesting that it maybe a biomarker of JIA. Our logistic regression analysis suggests that IL10 might have a protective effect on disease, as might be anticipated by its inhibitory activity.

Some cytokines were barely detected in the serum in a majority of subjects detected in our study. For example, undetectable levels of IL2, and IFN $\gamma$ have been reported by other investigators $[34,36]$. On the other hand, some of the results described here have not previously been reported by others. For instance some authors have reported finding no significant elevations in the levels of IL1 $\beta$, IL8, or TNF $\alpha[2,4,8,33]$. Differences in the results reported in this study and others could reflect heterogeneity of the different JIA cohorts. Other differences could be due to methodological issues, such as test specimen (serum versus plasma) and assay methodology. It is likely that some cytokines are more elevated in the synovial fluid and not in the serum, especially in children with persistently oligoarticular JIA.

Our study has several strengths. Our cohort of 80 JIA patients and 80 pediatric controls is larger than most series. Our patients have been classified using the ILAR criteria, which results in more homogeneous subtypes compared to earlier studies. To our knowledge sCD154 has not been measured in JIA patients before. We also measured several other cytokines previously implicated in JIA. The multiplex assay used small volumes of serum to assay thirteen cytokines. This method has also been successfully used by de Jager et al[33], but SCD154 and sIL2R were not among the cytokines included in their study. They also found that IL6 differed between controls and patients. We have used an objective partially automated multianalyte assay which we have found to reliably measure cytokines and other analytes in a variety of disorders including immune deficiency [26], coronary artery disease [37] and acute rheumatic fever [38]. We believe the differences in cytokine profiles, as well as in the inflammatory marker sCD154, suggest that these might play a role in the pathogenesis of at least some subtypes of JIA.

The past decade has seen the emergence of biological therapeutic agents directed against several mediators of inflammation. Our findings of elevated TNFa is in agreement with the response seen with anti-TNF therapy in children with JIA. The elevated levels of IL1 $\beta$ and IL6 support the roles for biological agents targeting these cytokines as well. Finally, sCD154 could also be a potential target of biological therapy, although some studies in individuals with SLE raise the concern for pro-thrombotic effects, possibly due to effects of these agents on platelets 
and/or the endothelium [39]. If the importance of the CD40-CD154 pathway in JIA is confirmed, and safety concerns could be addressed, therapy directed at inhibiting this pathway deserves further exploration in JIA.

\section{Conclusion}

We have demonstrated that SCD154 levels are elevated in sera from children with JIA. Furthermore, sCD154 levels correlated with several other pro-inflammatory cytokines, which are also elevated in children with JIA. The potential implications of sCD154 as a biomarker for treatment and monitoring patients is of particular appeal since sCD154 is a molecule associated with $\mathrm{T}$ cell activation and may play a role in the pathogenesis of JIA.

\section{Competing interests}

The authors declare that they have no competing interests.

\section{Authors' contributions}

SP conceived of the study, participated in the design and coordination of study, performed the statistical analysis, and wrote the manuscript, TBM Carried out the Luminex analyses, and helped to draft the manuscript, AET Participated in the design of the study, helped to coordinate the study, and to draft the manuscript, AW Participated in the design of the study, sample acquisition, and drafting of the manuscript, BC Enrolled subjects, involved in acquisition of samples and assisted with data collection, ASZ Participated in the design of the study, and helped to draft the manuscript, BMcN Participated in the design of the study, and helped to draft the manuscript, JFB Participated in the design of the study, and helped to draft the manuscript, HRH Senior author Participated in the design of the study, directed the Luminex analyses, and helped to draft the manuscript. All authors participated in the writing, read and approved the final manuscript.

\section{Acknowledgements}

The authors would like to thank Bonnie LaFleur PhD MPH, for critical review of the manuscript and helpful comments.

Supported by, The National Institute of Arthritis and Musculoskeletal and Skin Diseases (AR50 177), The National Center for Research Resources (RR00064), The Arthritis Foundation, and The Val A Browning Charitable Foundation, The Clinical Genetics Research Program, The Primary Children's Medical Center Foundation, and the Children's Health Research Center, Salt Lake City, UT.

\section{References}

I. Woo P: The cytokine network in juvenile chronic arthritis. Rheum Dis Clin North Am 1997, 23(3):49|-498.

2. Madson KL, Moore TL, Lawrence JM 3rd, Osborn TG: Cytokine levels in serum and synovial fluid of patients with juvenile rheumatoid arthritis. J Rheumatol I994, 2 I(12):2359-2363.

3. Ozen S, Saatci U, Bakkaloglu A, Ozdemir O, Besbas N, Kirazli S, Ozdemir S: Interleukin-I, -6, and -8 levels in juvenile chronic arthritis. Clin Rheumatol 1997, 16(2): 173-178.
4. Yilmaz M, Kendirli SG, Altintas D, Bingol G, Antmen B: Cytokine levels in serum of patients with juvenile rheumatoid arthritis. Clin Rheumatol 200I, 20(I):30-35.

5. Lotito AP, Campa A, Silva CA, Kiss MH, Mello SB: Interleukin I 8 as a marker of disease activity and severity in patients with juvenile idiopathic arthritis. J Rheumatol 2007, 34(4):823-830.

6. Shahin AA, Shaker OG, Kamal N, Hafez HA, Gaber W, Shahin HA: Circulating interleukin-6, soluble interleukin-2 receptors, tumor necrosis factor alpha, and interleukin- 10 levels in juvenile chronic arthritis: correlations with soft tissue vascularity assessed by power Doppler sonography. Rheumatol Int 2002, 22(2):84-88.

7. De Benedetti F, Robbioni P, Massa M, Viola S, Albani S, Martini A: Serum interleukin-6 levels and joint involvement in polyarticular and pauciarticular juvenile chronic arthritis. Clin Exp Rheumatol 1992, I0(5):493-498.

8. Mangge H, Kenzian H, Gallistl S, Neuwirth G, Liebmann P, Kaulfersch W, Beaufort F, Muntean W, Schauenstein K: Serum cytokines in juvenile rheumatoid arthritis. Correlation with conventional inflammation parameters and clinical subtypes. Arthritis Rheum 1995, 38(2):2I I-220.

9. Silverman ED, Laxer RM, Nelson DL, Rubin LA: Soluble interleukin-2 receptor in juvenile rheumatoid arthritis. I Rheumatol 199|, 18(9): |398-1402.

10. Grewal IS, Flavell RA: CD40 and CDI54 in cell-mediated immunity. Annual review of immunology 1998, 16: I I-135.

II. Grewal IS, Flavell RA: A central role of CD40 ligand in the regulation of CD4+ T-cell responses. Immunology today 1996, I7(9):4|0-4|4.

12. Banchereau J, Bazan F, Blanchard D, Briere F, Galizzi JP, van Kooten $C$, Liu YJ, Rousset F, Saeland S: The CD40 antigen and its ligand. Annual review of immunology 1994, I 2:88I-922.

13. Spriggs MK, Fanslow WC, Armitage RJ, Belmont J: The biology of the human ligand for CD40. Journal of clinical immunology 1993 , 13(6):373-380.

14. Dechanet J, Grosset C, Taupin JL, Merville P, Banchereau J, Ripoche J, Moreau JF: CD40 ligand stimulates proinflammatory cytokine production by human endothelial cells. J Immunol 1997, I59(II):5640-5647.

15. Koshy M, Berger D, Crow MK: Increased expression of CD40 ligand on systemic lupus erythematosus lymphocytes. J Clin Invest 1996, 98(3):826-837.

16. Liu MF, Chao SC, Wang CR, Lei HY: Expression of CD40 and CD40 ligand among cell populations within rheumatoid synovial compartment. Autoimmunity 200 I, 34(2): 107-II3.

17. Pietravalle F, Lecoanet-Henchoz S, Blasey H, Aubry JP, Elson G, Edgerton MD, Bonnefoy JY, Gauchat JF: Human native soluble CD40L is a biologically active trimer, processed inside microsomes. J Biol Chem 1996, 27 I (I I):5965-5967.

18. Vakkalanka RK, Woo C, Kirou KA, Koshy M, Berger D, Crow MK: Elevated levels and functional capacity of soluble CD40 ligand in systemic lupus erythematosus sera. Arthritis Rheum 1999, 42(5):87|-88I.

19. Tamura N, Kobayashi S, Kato K, Bando H, Haruta K, Oyanagi M, Kuriyama M, Kipps TJ, Hashimoto H: Soluble CDI54 in rheumatoid arthritis: elevated plasma levels in cases with vasculitis. J Rheumatol 200I, 28(I 2):2583-2590.

20. Ludwiczek O, Kaser A, Tilg H: Plasma levels of soluble CD40 ligand are elevated in inflammatory bowel diseases. International journal of colorectal disease 2003, I8(2): | 42-I47.

21. Allanore $Y$, Borderie D, Meune $C$, Lemarechal $H$, Weber S, Ekindjian OG, Kahan A: Increased plasma soluble CD40 ligand concentrations in systemic sclerosis and association with pulmonary arterial hypertension and digital ulcers. Ann Rheum Dis 2005, 64(3):48I-483.

22. Komura K, Sato S, Hasegawa M, Fujimoto M, Takehara K: Elevated circulating CD40L concentrations in patients with systemic sclerosis. J Rheumatol 2004, 3 I (3):5 I 4-5 I9.

23. Goules A, Tzioufas AG, Manousakis MN, Kirou KA, Crow MK, Routsias JG: Elevated levels of soluble CD40 ligand (sCD40L) in serum of patients with systemic autoimmune diseases. Journal of autoimmunity 2006, 26(3): 165-17I.

24. Petty RE, Southwood TR, Manners P, Baum J, Glass DN, Goldenberg J, He X, Maldonado-Cocco J, Orozco-Alcala J, Prieur AM, SuarezAlmazor ME, Woo P: International League of Associations for Rheumatology classification of juvenile idiopathic arthritis: 
second revision, Edmonton, 200I. I Rheumatol 2004, 3I(2):390-392.

25. Fulton RJ, McDade RL, Smith PL, Kienker LJ, Kettman JR Jr.: Advanced multiplexed analysis with the FlowMetrix system. Clinical chemistry 1997, 43(9): I749-1756.

26. Martins TB, Pasi BM, Pickering JW, Jaskowski TD, Litwin CM, Hill HR: Determination of cytokine responses using a multiplexed fluorescent microsphere immunoassay. American journal of clinical pathology 2002, I I 8(3):346-353.

27. Martins TB, Pasi BM, Litwin CM, Hill HR: Heterophile antibody interference in a multiplexed fluorescent microsphere immunoassay for quantitation of cytokines in human serum. Clin Diagn Lab Immunol 2004, I I(2):325-329.

28. Staros JV, Wright RW, Swingle DM: Enhancement by N-hydroxysulfosuccinimide of water-soluble carbodiimide-mediated coupling reactions. Analytical biochemistry 1986, I 56(I):220-222.

29. MacDonald KP, Nishioka Y, Lipsky PE, Thomas R: Functional CD40 ligand is expressed by $\mathbf{T}$ cells in rheumatoid arthritis. J Clin Invest 1997, 100(9):2404-24I4.

30. Sekine C, Yagita H, Miyasaka N, Okumura K: Expression and function of CD40 in rheumatoid arthritis synovium. I Rheumatol 1998, 25(6): 1048-1053.

31. Durie FH, Fava RA, Foy TM, Aruffo A, Ledbetter JA, Noelle RJ: Prevention of collagen-induced arthritis with an antibody to gp39, the ligand for CD40. Science I993, 26 I (5 I 26): I 328-1330.

32. Wynne-Roberts CR, Anderson CH, Turano AM, Baron M: Lightand electron-microscopic findings of juvenile rheumatoid arthritis synovium: comparison with normal juvenile synovium. Semin Arthritis Rheum 1978, 7(4):287-302.

33. de Jager W, Hoppenreijs EP, Wulffraat NM, Wedderburn LR, Kuis W, Prakken B]: Blood and synovial fluid cytokine signatures in patients with juvenile idiopathic arthritis: a cross-sectional study. Ann Rheum Dis 2007, 66(5):589-598.

34. Lepore L, Pennesi M, Saletta S, Perticarari S, Presani G, Prodan M: Study of IL-2, IL-6, TNF alpha, IFN gamma and beta in the serum and synovial fluid of patients with juvenile chronic arthritis. Clin Exp Rheumatol 1994, I 2(5):56I-565.

35. De Benedetti F, Pignatti P, Bernasconi S, Gerloni V, Matsushima K, Caporali R, Montecucco CM, Sozzani S, Fantini F, Martini A: Interleukin 8 and monocyte chemoattractant protein-I in patients with juvenile rheumatoid arthritis. Relation to onset types, disease activity, and synovial fluid leukocytes. J Rheumatol 1999, 26(2):425-431.

36. Muller K, Pedersen FK, Wiik A, Bendtzen K: Lymphokines and soluble interleukin-2 receptors in juvenile chronic arthritis. Clinical and laboratory correlations. Rheumatol Int 1992, I 2(3):89-92.

37. Martins TB, Anderson JL, Muhlestein JB, Horne BD, Carlquist JF, Roberts WL, Carlquist JF: Risk factor analysis of plasma cytokines in patients with coronary artery disease by a multiplexed fluorescent immunoassay. American journal of clinical pathology 2006, I 25(6):906-9|3.

38. Martins TB, Augustine NH, Hill HR: Development of a multiplexed fluorescent immunoassay for the quantitation of antibody responses to group A streptococci. Journal of immunological methods 2006, 3 I 6( I-2):97-106.

39. Sidiropoulos PI, Boumpas DT: Lessons learned from anti-CD40L treatment in systemic lupus erythematosus patients. Lupus 2004, I3(5):39|-397.
Publish with Biomed Central and every scientist can read your work free of charge

"BioMed Central will be the most significant development for disseminating the results of biomedical research in our lifetime. "

Sir Paul Nurse, Cancer Research UK

Your research papers will be:

- available free of charge to the entire biomedical community

- peer reviewed and published immediately upon acceptance

- cited in PubMed and archived on PubMed Central

- yours - you keep the copyright

Submit your manuscript here:

http://www.biomedcentral.com/info/publishing_adv.asp
BioMedcentral 